\title{
Comparison of Carslaw and Jaeger method and finite element method to estimate temperature of soil in Antarctica
}

\author{
${ }^{1}$ School of Earth and Environmental Sciences, Seoul National University, Seoul 08826, Republic of Korea \\ ${ }^{2}$ Department of Geology, Kangwon National University, Chuncheon 24341, Republic of Korea; *Corresponding author, \\ E-mail:hydrolee@kangwon.ac.kr \\ ${ }^{3}$ Critical Zone Frontier Research Laboratory (CFRL), Kangwon National University, Chuncheon 24341, Republic of Korea
}

(Received: April 12, 2017; Revised accepted: August 24, 2017)

http://dx.doi.org/10.18814/epiiugs/2018/v41i1/018005

We examined the Carslaw and Jaeger (C-J) method to compute the temperature profile of inner soil in a region of Antarctica. The solution of the C-J method is expressed as an integral of the convolution of surface temperature and a transfer function, and can be used to determine the thermal diffusivity of soil. The obtained solution, however, is only an approximation of the integral because the fieldmeasured temperature data used as the surface temperature are usually obtained at a specific time interval, causing some error in the C-J method. This error is identified in the present study through mathematical examples which graphically compare the results obtained from finite element analysis and the C-J method. The error increases as the surface temperature changes abruptly or with a larger thermal diffusivity. As the time interval increases, the error tends to increase for the C-J method, implying that the time interval needs to be small enough to ensure that the analysis is accurate. This study, therefore, recommends a finite element method to solve heat conduction problems related to estimating the temperature of inner soil, because this method is not dependent on the measurement time interval.

\section{Introduction}

Climate change affects the active layer of permafrost in and around the Arctic and Antarctic regions, directly and indirectly, by changing its physical and ecological structure and function (Anisimov et al., 1997). By applying the climate change prediction scenario of Intergovernmental Panel on Climate Change, the National Snow and Ice Data Center at the University of Colorado at Boulder reported that $29-59 \%$ of the world's permafrost would melt and release large amounts of carbon by 2200 due to the increase in the earth's average temperature (Schaefer et al., 2011). Permafrost is closely connected with climate change because it plays a role in regulating carbon dioxide levels (Koven et al., 2011). Therefore, a quantitative analysis of the heat transfer problem for permafrost becomes important, and understanding its thermal properties is essential (Lunardini, 1981;
Hinkel, 1997; Boike et al., 1998; Frauenfeld et al., 2004).

Thermal diffusivity is one of the most important thermal properties of soil. Nicolsky et al. (2009) reported that there are several in-situ methods for measuring thermal properties, including needle probes (Herzen and Maxwell, 1959), divided bar (Birch, 1950), borehole relaxation (Wilhelm, 1990), non-linear fitting (Da-Xin, 1956), thermal gradients pulse (Silliman and Neuzil, 1990), and estimation from thermal gradients (Somerton, 1992). The generally adopted method for estimating thermal diffusivity is the Carslaw and Jaeger (C-J) method (1986), which gives the temperature distribution of soil at different depths and times. The thermal diffusivity of soil can be found by best-matching the calculated temperature with the measured temperature of the inner soil (Roth and Boike, 2001; Pringle et al., 2003; Han et al., 2006; Kim et al., 2014). The C-J method needs a timeseries of surface temperature; its solution is expressed as an integral of the convolution of a surface temperature function and a transfer function. Field-measured temperature is obtained at a specified time interval. Because the integral uses the average temperature of a time interval, even a very short one, an error between the accurate solution and its approximation is inevitable. In order to reduce the error, it is important to adjust the time interval and the depth at which field temperature is measured, with respect to a range of thermal diffusivities.

This study examines the C-J method using mathematical examples. First, results from the finite element method (FEM) and the C-J method are graphically displayed for a simple hypothetical temperature boundary condition, and the error trend is examined. Next, surface temperature data are generated using field-measured data from the Antarctic region and used as the input for the two analysis methods. The applicability of the finite element method is then contrasted with that of the C-J method, and the former is recommended as a tool to estimate the temperature distribution, and subsequently the thermal diffusivity, of inner soil.

\section{Methods for Estimating Thermal Diffusivity of Soil}

\section{Methods for Determining Thermal Diffusivity using Mea- sured Temperature}

The C-J method, which this study focuses on, is similar to other 
methods that only require the field-measured temperature to determine soil thermal diffusivity - including, according to Pringle et al. (2003), the Simple Fourier Methods of Carson (Carson, 1963), the Perturbed Fourier Method (Hurley and Wiltshire, 1993), and the Graphical Finite Difference Method (Trodahl et al., 2000, 2001; Nicolsky et al., 2007). The traditional finite element analysis for heat conduction can be used. The C-J method solves a governing differential equation for one-dimensional thermal diffusion as follows:

$$
\frac{\partial T}{\partial t}=\alpha \frac{\partial^{2} T}{\partial z^{2}},
$$

where $T$ is the temperature $\left({ }^{\circ} \mathrm{C}\right), t$ is the time (s), $z$ is the depth (m), and $\alpha$ is the thermal diffusivity $\left(\mathrm{m}^{2} / \mathrm{s}\right)$.

For a semi-infinite medium without any heat source or sink, with an initial temperature of $0^{\circ} \mathrm{C}$ and a surface temperature of $T(0, t)$, the solution of Equation (1) is given in the form of an integral of the convolution of the surface temperature function and the transfer function $f_{T}$ (Carslaw and Jaeger, 1986):

$$
\begin{aligned}
& T(z, t)=\int_{0}^{t} T(0, \tau) f_{T}(t-\tau, z) d \tau, \\
& f_{T}(t, z)=\frac{z}{2\left[\pi \alpha t^{3}\right]} \exp \left(-\frac{z^{2}}{4 \alpha t}\right) .
\end{aligned}
$$

By measuring the surface temperature for a time period, the C-J method allows the calculation of temperature at different depths. Comparison of the calculated and measured temperatures gives the optimal value of the thermal diffusivity estimates.

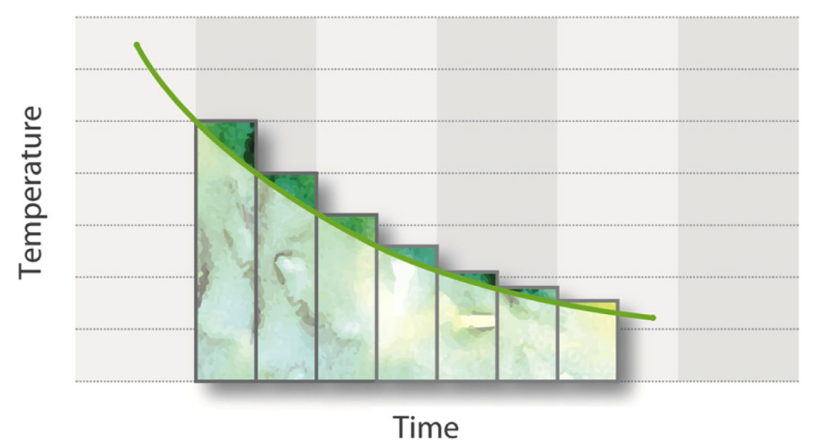

(a)

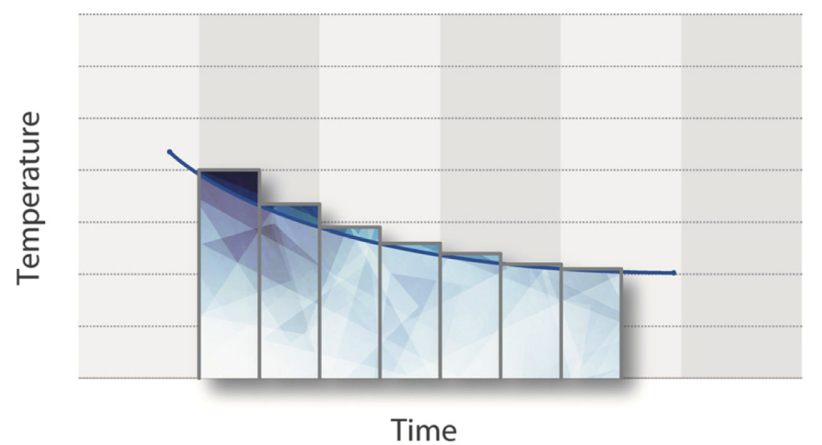

(c)

\section{An Inquiry into Carslaw and Jaeger Method}

Figure 1 shows the area under a curve for different slopes and different time intervals. As the slope of the curve or the time interval increases, the error between an accurate area and its approximation increases. The C-J method is expressed as an integral form of Equation (2) and thus requires continuous surface temperature data or a very small time interval which can be viewed as nearly continuous. In reality, however, time intervals are measured discretely (e.g., $10 \mathrm{~min}$, $30 \mathrm{~min}, 1 \mathrm{~h}$, or $2 \mathrm{~h}$ ) because of several issues, including the limitations of data-storing devices or power supply problems in the field. As a result, adopting the integration concept shown in Figure 1 will not result in the accurate integration of Equation (2); instead, it approximates the sum of the areas of the rectangular columns shown in Figure 1 and can be represented as follows:

$$
T(z, t)=\int_{0}^{t} T(0, \tau) f_{T}(t-\tau, z) d \tau \approx \sum_{j=1}^{n} \sum_{i=1}^{j} T(0, \tau) f_{T}(t-\tau, z) \Delta t .
$$

The approximation can be good enough to delineate the temperature distribution in the soil, but the errors may be very large under some conditions. This section identifies this problem with the C-J method for a hypothetical sine curve boundary condition.

Figure 2 shows the temperature distributions in semi-infinite soil at the time intervals of 0.1 and $2 \mathrm{~h}$, solved with the FEM and the C-J method, with an initial temperature of $0{ }^{\circ} \mathrm{C}$ and a heat diffusivity of 1 $\times 10^{-7} \mathrm{~m}^{2} / \mathrm{s}$. Finite element procedures are widely used in structural problems and in non-structural problems, such as heat transfer and field and fluid flow problems (Bathe, 1996). The solution from the

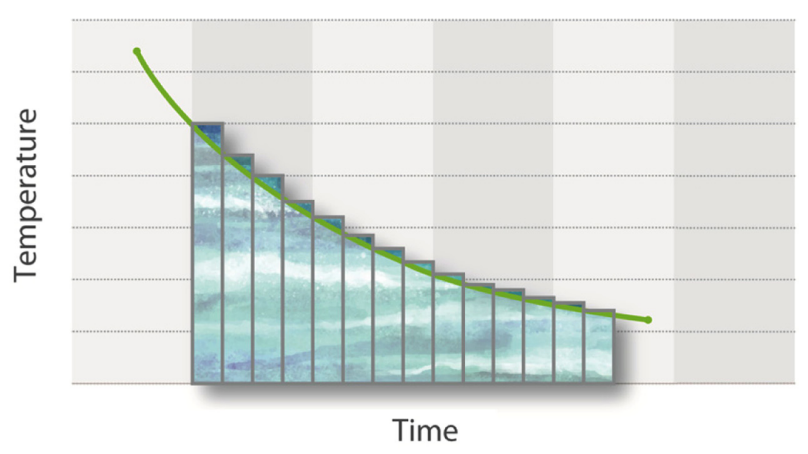

(b)

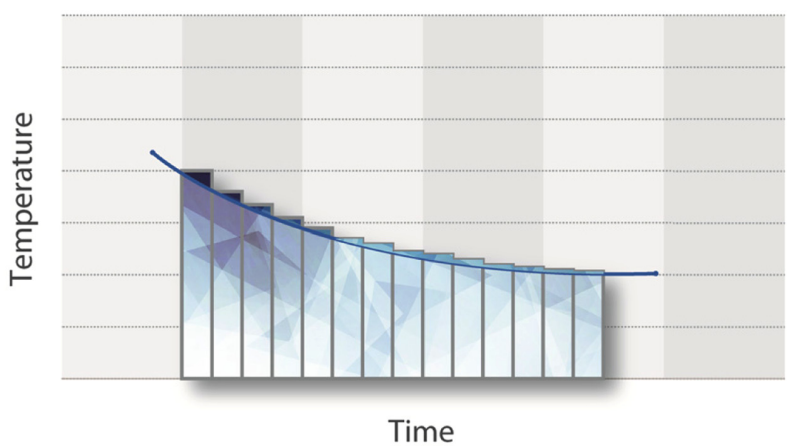

(d)

Figure 1. Schematic diagram of the approximation of area under a curve for different slopes of the curve and for different time intervals. The area under a curve can be approximated as the sum of areas of rectangular column elements. This value approaches an exact value as the width of column element gets smaller (b) is the better approximation than (a)). The slope of the curve also influences the precision of the area approximation ((c) has better performance than (a) because the curve of (a) is steeper). 


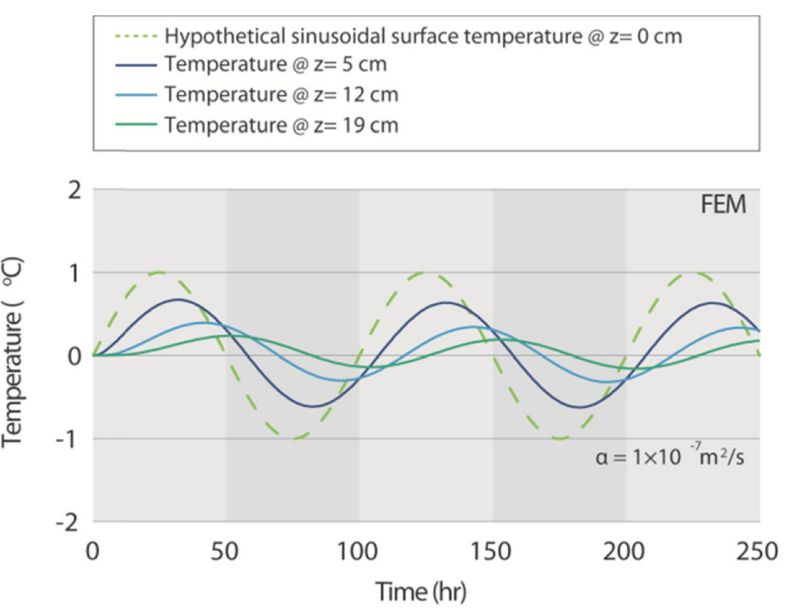

(a)

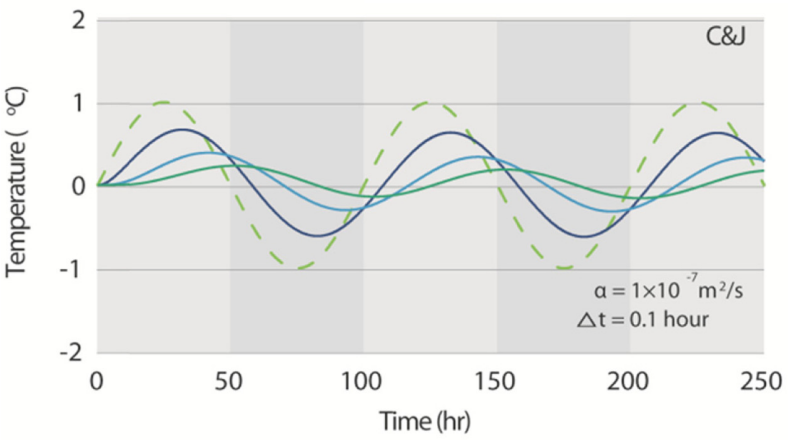

(c)

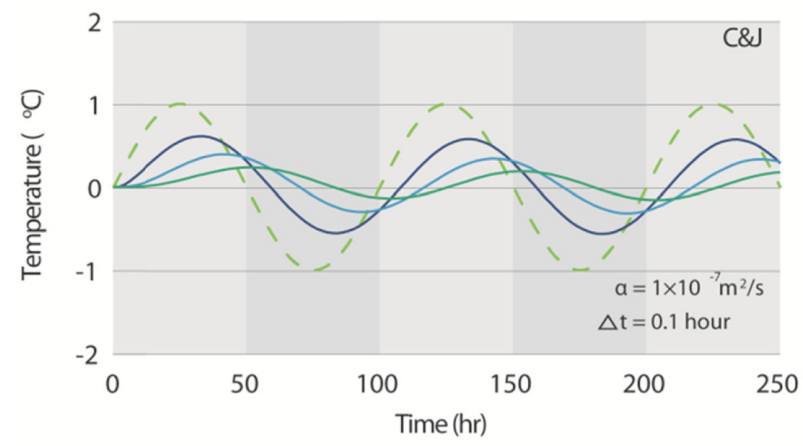

(e)

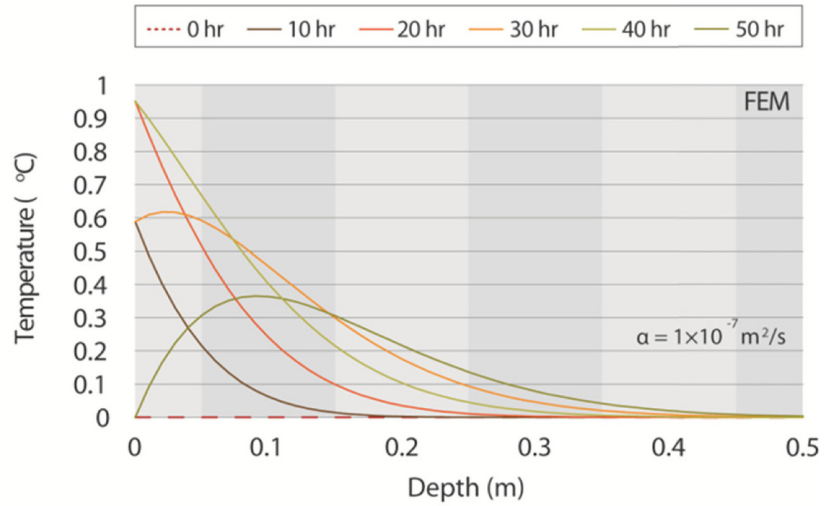

(b)

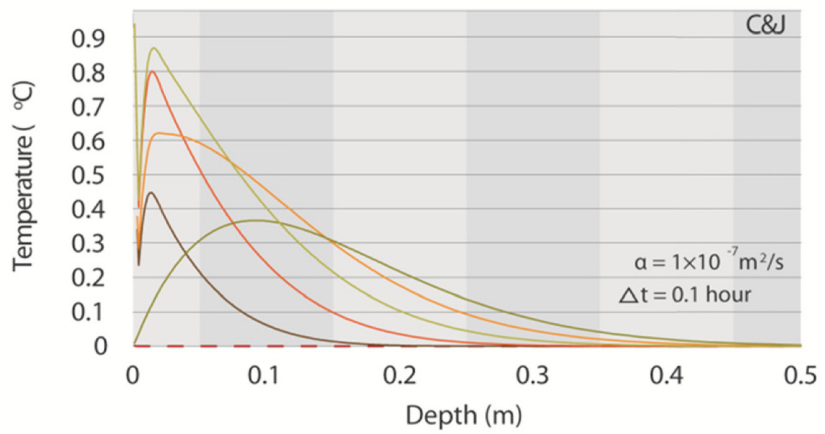

(d)

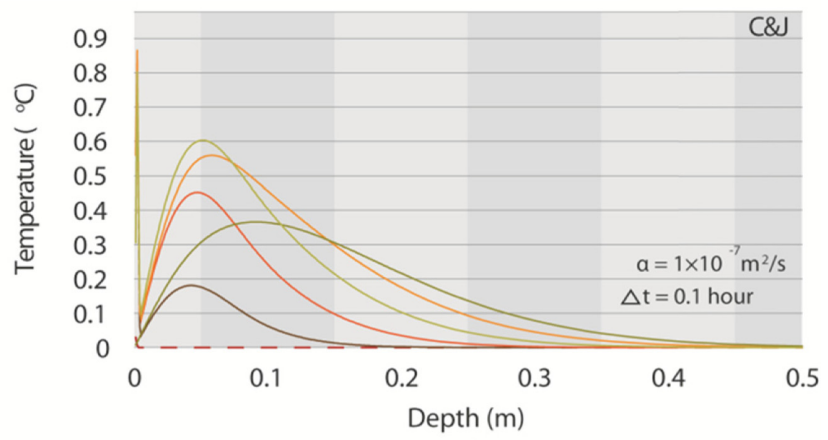

(f)

Figure 2. Soil temperature distributions calculated from the FEM and the C-J method for different time intervals.

FEM is accurate and the detailed principle of the method can be found in related literature. However, the C-J method produces a large error at a longer time interval, and cannot accurately estimate soil temperatures at near-surface areas because of a large error near the boundary. We cannot use the C-J method near the boundary because the temperature change is abrupt near the surface; compared to near-surface areas, inner soil experiences a much smaller temperature change. With the concept of area approximation, the small temperature change allows for a larger width of the rectangular columns in Figure 1, implying that a longer time interval is acceptable to achieve the same accuracy. Therefore, care should be taken when adopting the C-J method because the resulting temperature estimates might not be as accurate as desired, depending on the thermal diffusivity and time interval at the measurement site.

Figure 3 shows the result of an analysis with a thermal diffusivity of $9 \times 10^{-7} \mathrm{~m}^{2} / \mathrm{s}$ and a time interval of 2 hours. Comparing Figures $3 \mathrm{c}$ and $\mathrm{d}$ with Figures $2 \mathrm{e}$ and $\mathrm{f}$ shows that the C-J method produces a larger error for the same time interval when the thermal diffusivity is greater. This is because the greater thermal diffusivity implies that heat is conducted more rapidly into inner soil. Therefore, a greater thermal diffusivity confines the applicability of the C-J method to deeper soils.

\section{Estimation of Soil Temperature using a Surface Tem- perature Measured in the Antarctica}

This section compares temperature distributions calculated using the FEM and the C-J method with surface temperatures measured at the King Sejong Station in Antarctica (see Fig. 4). The surface temperatures were measured at 10-min intervals (Jeon et al., 2016; Lee et al., 2016). Surface temperature data at different time intervals $(20,30$, 


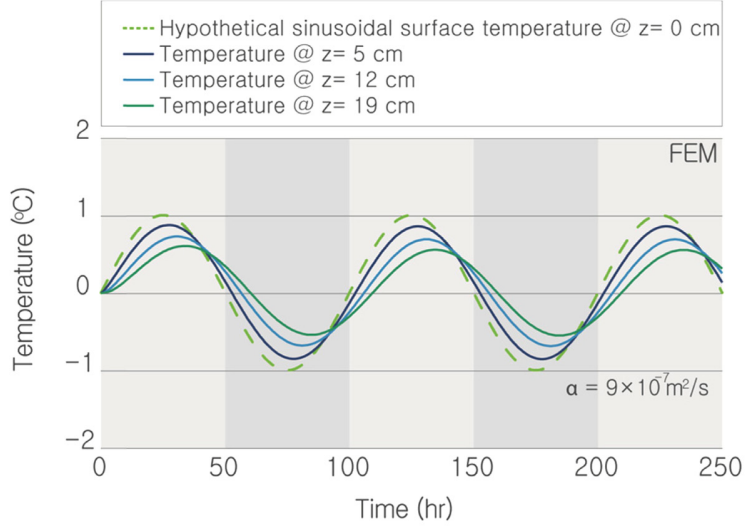

(a)

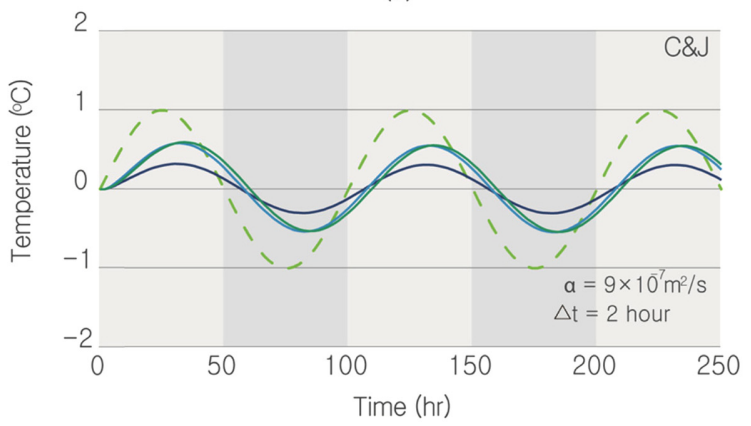

(c)

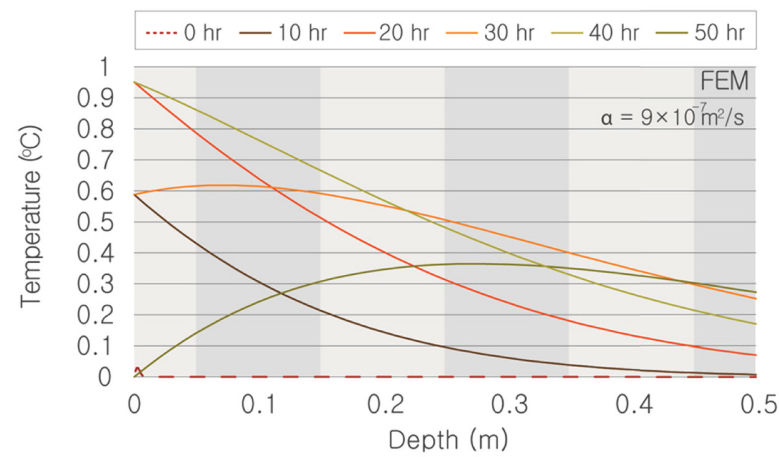

(b)

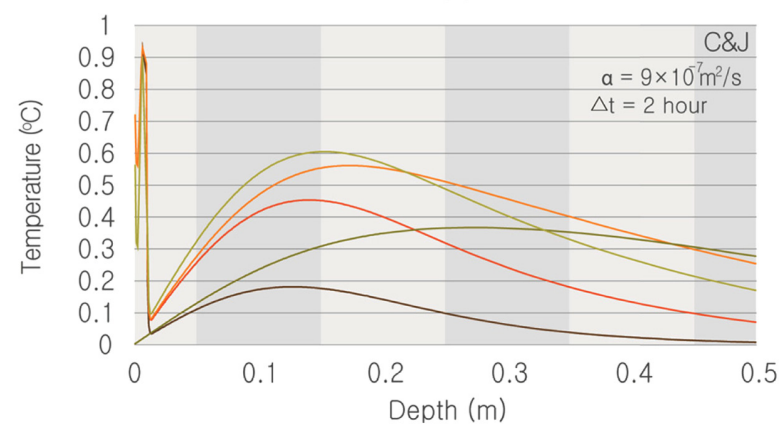

(d)

Figure 3. Soil temperatures calculated from the FEM and the C-J method for different values of thermal diffusivity.

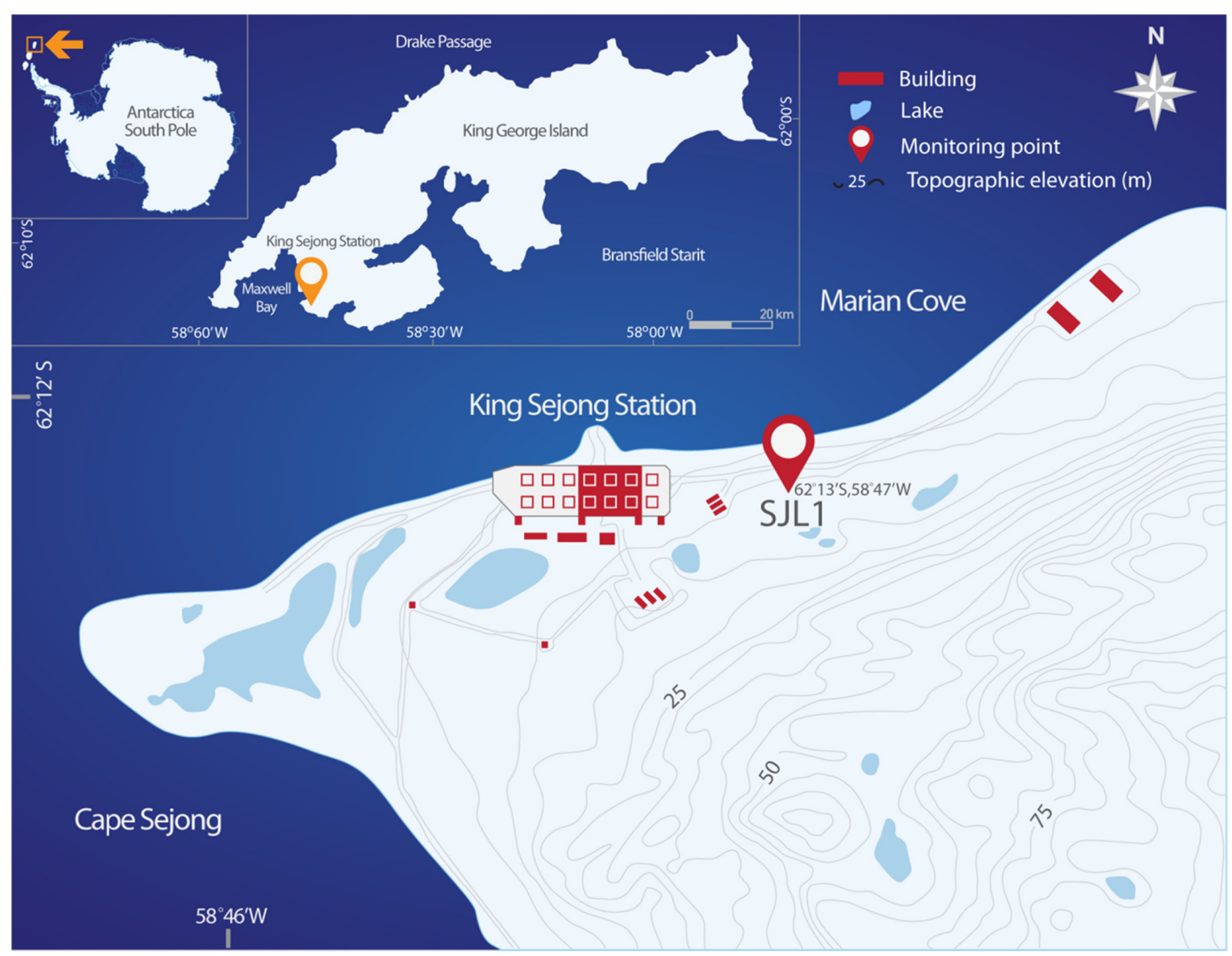

Figure 4. Surface temperature monitoring location at the King Sejong Station in the Antarctica. The soil temperature data are from Jeon et al. (2016). 

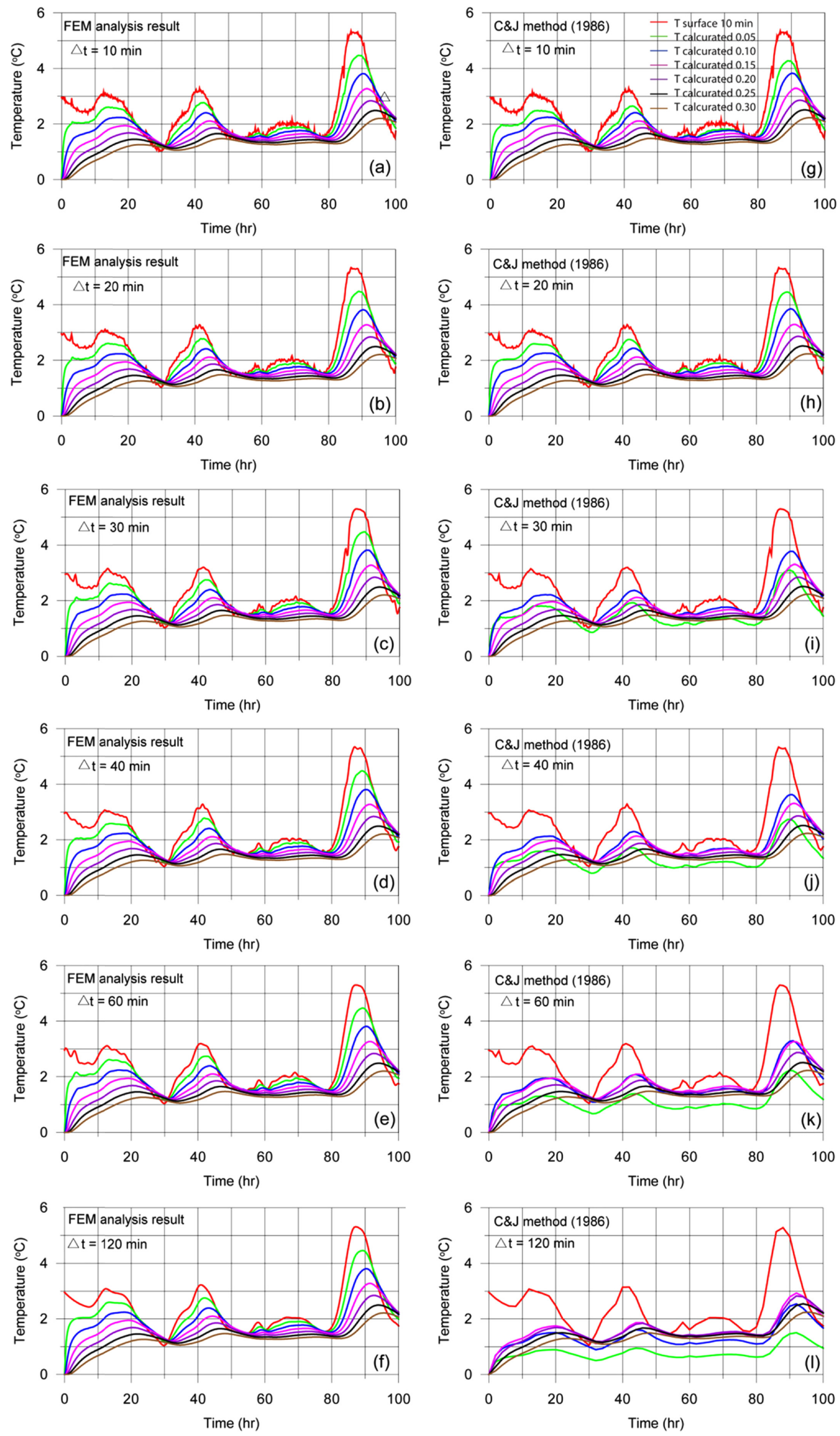

Figure 5. Temperature changes in soil for different time intervals (first 100 h), measured at the King Sejong Station in Antarctica. 
40, 60, and $120 \mathrm{~min}$ ) were also generated using the original data for use in the two analysis methods. The surface temperature at the 20-min interval, for example, was determined by sampling data from every other 10-min interval. The change in surface temperature for each time interval can be seen in Figure 5. The examples used in this section assume an initial temperature of $0{ }^{\circ} \mathrm{C}$ in the soil and a thermal diffusivity of $10 \times 10^{-7} \mathrm{~m}^{2} / \mathrm{s}$.

The surface temperatures were measured for almost 270 days; Figure 5 shows the analysis results of the first $100 \mathrm{~h}$. The two analysis methods involve the conduction mode of heat transfer and should be
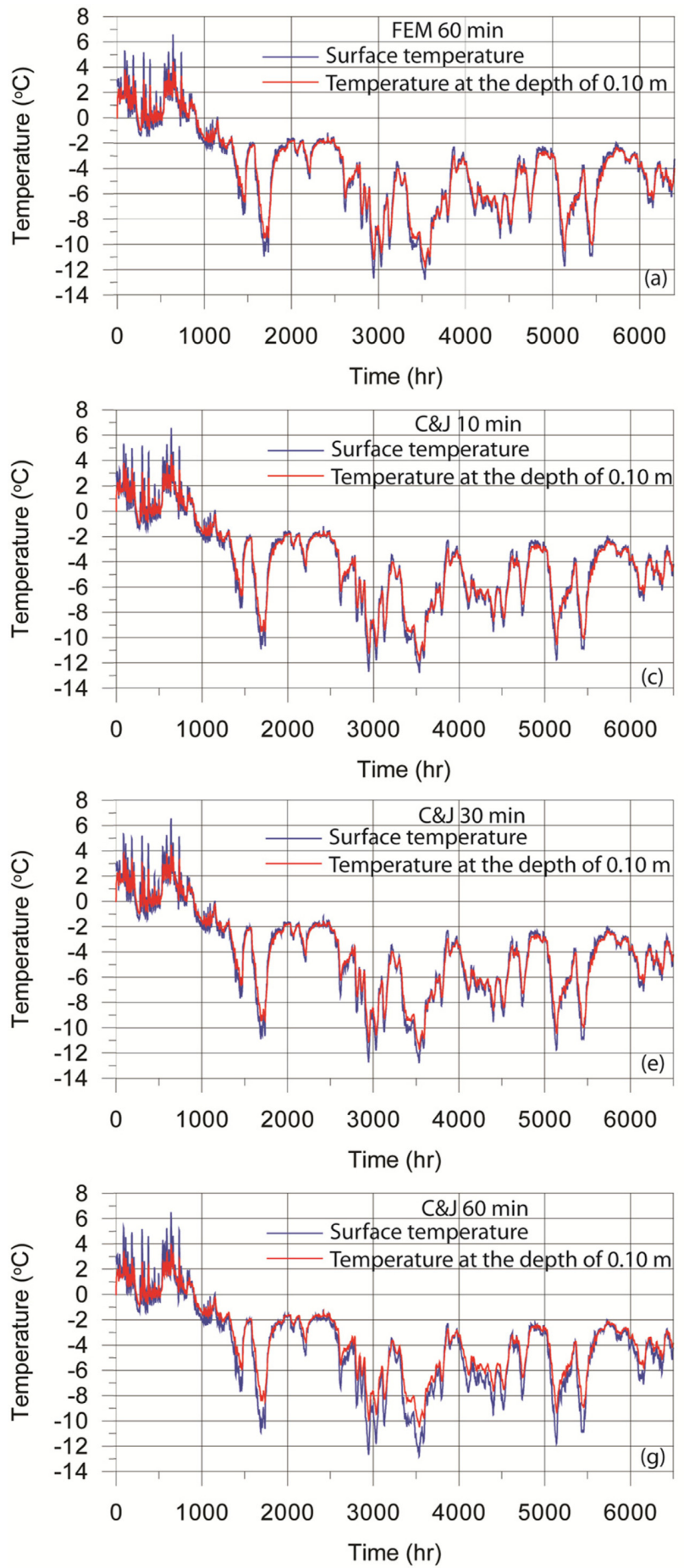

applied to the soil region of temperature lower than $0{ }^{\circ} \mathrm{C}$. Figure 5 also shows the conduction results at temperatures higher than $0^{\circ} \mathrm{C}$, but its main purpose is to show that the FEM and the C-J produce different results. However, later parts of the analysis show that the surface and the calculated inner soil temperatures fall below $0{ }^{\circ} \mathrm{C}$ for a long period (see Fig. 6). As shown in Figure 5, the C-J method calculates results with errors for longer time intervals. Figure 6 shows the surface temperature and calculated temperature at a depth of $0.1 \mathrm{~m}$, measured at different time intervals over the 270 days, using the two analysis methods. Again, it is indicated that the C-J method shows a larger error for
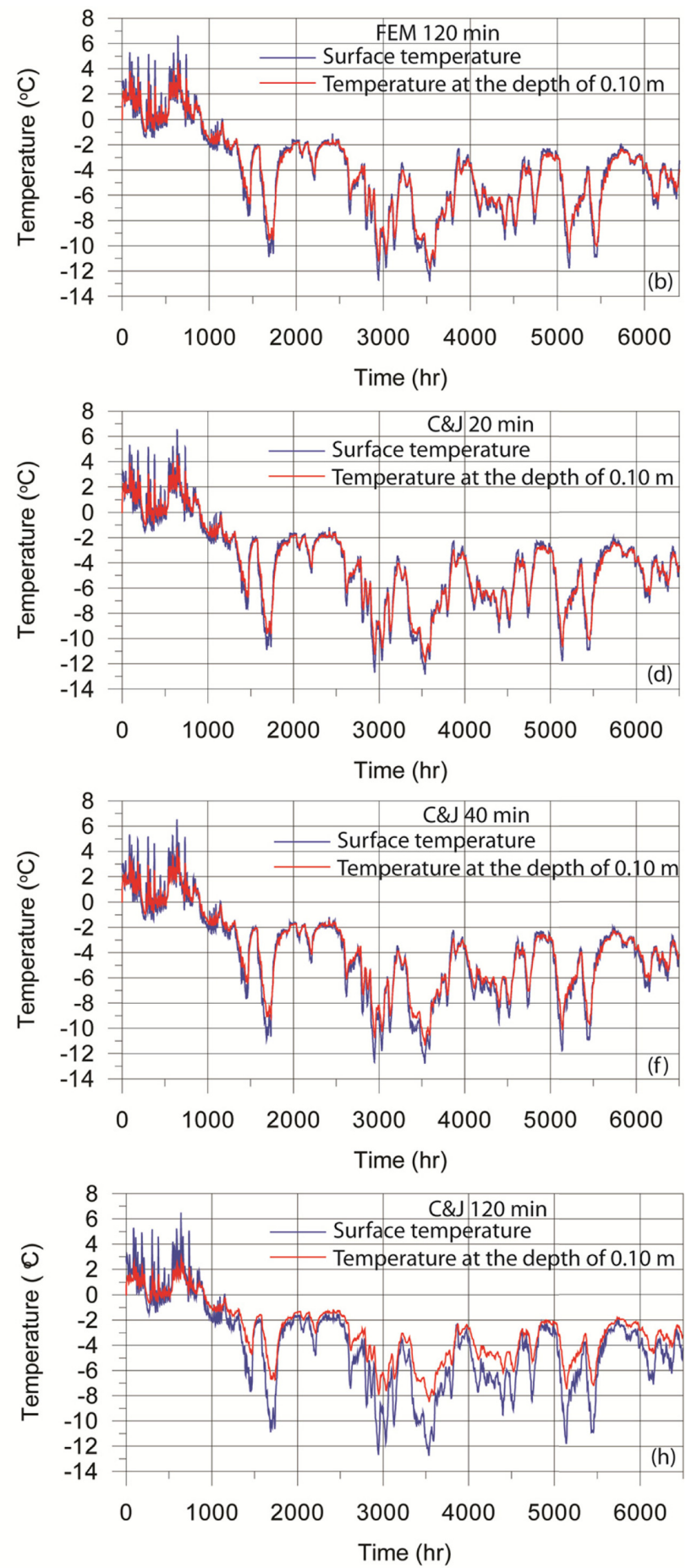

Figure 6. Surface temperature and soil temperature at the depth of $0.10 \mathrm{~m}$ for different time intervals (over 270 days). 


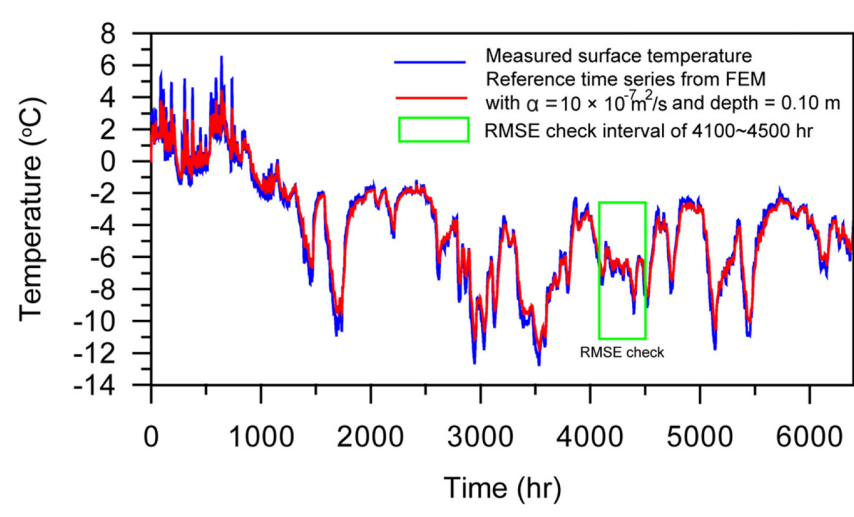

Figure 7. Reference time series from the FEM and the C-J method showing a time window for the optimum thermal diffusivity.

a longer time interval.

To quantitatively investigate the effects of the time interval and monitoring depth on thermal diffusivity, numerical experiments were performed for the surface temperatures measured at King Sejong Station. With a reference time series obtained from the application of finite element analysis to the measured surface temperatures, and with hypothetical thermal diffusivities of $5 \times 10^{-7}$ and $10 \times 10^{-7} \mathrm{~m}^{2} / \mathrm{s}$, repeated application of the C-J method to the measured surface temperatures gave estimates of the temperature time series for different depths. The best-fit thermal diffusivity was determined by minimizing root-meansquared-errors between the reference time series, and those from the C-J method, for a period between 4,100 and 4,500 h (see Fig. 7). The best-fit thermal diffusivities are shown in Figure 8, which indicates that the C-J method produces a good estimate of thermal diffusivity for a smaller value of thermal diffusivity, larger value of monitoring depth, and shorter measuring time interval.

\section{Conclusion}

This study examined the C-J method and the FEM to estimate the temperature distribution of inner soil, and reveals that the former produces some errors at the near-surface. This error increases in deeper soil when the thermal diffusivity is large, or when the surface temperature change is abrupt. This phenomenon is identified in example analyses with hypothetical and real boundary conditions. Thus, adoption of the C-J method requires careful consideration of the time interval, the depth at which temperature measurements are performed (because this depends on the thermal diffusivity), and changes in the surface temperature pattern. Determining the two factor combination (time interval and temperature-measuring depth) required, however, would not be easy. This study, therefore, recommends the FEM to estimate the temperature of inner soil because this method does not depend on the time interval and abrupt changes in surface temperature.

\section{Acknowledgements}

This research was financially supported by the National Research Foundation of Korea funded by the Ministry of Education (NRF2015R1C1A2A01052726) and the International Collaborative Energy Technology R\&D Program of the Korea Institute of Energy Technology Evaluation and Planning (KETEP), granted financial resource from the Ministry of Trade, Industry \& Energy, Republic of Korea (No. 20168510050070). We appreciate the handling editor' and reviewer's comments to improve this paper.

Figure 8. Best fit estimation of thermal diffusivities by application of C-J method. $($ a $)=5 \times 10^{-7}$ $\mathrm{m}^{2} / \mathrm{s}$ and $(\mathrm{b})=10 \times 10^{-7} \mathrm{~m}^{2} / \mathrm{s}$. 


\section{References}

Anisimov, O.A., Shiklomanov, N.I., and Nelson, F.E., 1997, Global warming and active-layer thickness: results from transient general circulation models. Global and Planetary Change, v. 15, pp. 61-77.

Bathe, K., 1996, Finite Element Procedures ( ${ }^{\text {nd }}$ edition). Prentice Hall, Upper Saddle River, $1037 \mathrm{p}$.

Birch, F., 1950, Flow of heat in the Front Range, Colorado. Geological Society of America Bulletin, v. 61, pp. 567-630.

Boike, J., Roth, K., and Overduin, P.P., 1998, Thermal and hydrologic dynamics of the active layer at a continuous permafrost site (Taymyr Peninsula, Siberia). Water Resources Research, v. 34, pp. 355-363.

Carslaw, H.J., and Jaeger, J.C., 1986, Conduction of Heat in Solids ( $2^{\text {nd }}$ edition). Oxford University Press, New York, $510 \mathrm{p}$.

Carson, J.E., 1963, Analysis of soil and air temperatures by Fourier techniques. Journal of Geophysical Research, v. 68, pp. 2217-2232.

Da-Xin, L., 1986, Non-linear fitting method of finding equilibrium temperature from BHT data. Geothermics, v. 15, pp. 657-664.

Frauenfeld, O.W., Zhang, T., Barry, R.G., and Gilichinsky, D., 2004, Interdecadal changes in seasonal freeze and thaw depths in Russia. Journal of Geophysical Research: Atmospheres, v. 109. DOI: 10.1029/2003JD004245

Han, U., Lee, C.K., Jeong, S.H., Lee, B.Y., and Nam, S.H., 2006, The studies on the temperature and thermal properties of the active layer soil at the Sejong Station, Antarctica. Journal of the Geological Society of Korea, v. 4, pp. 577-586.

Hinkel, K.M., 1997, Estimating seasonal values of thermal diffusivity in thawed and frozen soils using temperature time series. Cold Regions Science and Technology, v. 26, pp. 1-15.

Hurley, S., and Wiltshire, R.J., 1993, Computing thermal diffusivity from soil temperature measurements. Computers \& Geosciences, v. 19, pp. 475-477.

Jeon, W.H., Lee, J.Y., Lim, H.S., and Yoon, H.I., 2016, Comparison of thermal characteristics of soil in austral summer and winter at King Sejong Station, King George Island, Antarctica. Journal of the Geological Society of Korea, v. 52, pp. 901-915.

Kim, H., Lee, J.Y., and Lee, K.K., 2014, Thermal characteristics and bacterial diversity of forest soil in the Haean Basin of Korea. The Scientific World Journal, v. 2014. DOI: 10.1155/2014/247401

Koven, C.D., Ringeval, B., Friedlingstein, P., Ciais, P., Cadule, P., Khvorostyanov, D., and Tarnocai, C., 2011, Permafrost carbon-climate feedbacks accelerate global warming. Proceedings of the National Academy of Sciences of the United States of America, v. 108, pp. 14769-14774.

Lee, J.Y., Lim, H.S., and Yoon, H.I., 2016, Thermal characteristics of soil and water during summer at King Sejong Station, King George Island, Antarctica. Geosciences Journal, v. 20, pp. 503-516.

Lunardini, V.J., 1981, Heat Transfer in Cold Climates. Van Nostrand Reinhold Company, New York, $731 \mathrm{p}$.

McGuinness, M.J., Collins, K., Trodahl, H.J., and Haskell, T.G., 1998, Nonlinear thermal transport and brine convection in first year sea ice. Annals of Glaciology, v. 27, pp. 471-476.

Nicolsky, D.J., Romanovsky, V.E., and Tipenko, G.S., 2007, Using in-situ temperature measurements to estimate saturated soil thermal properties by solving a sequence of optimization problems. The Cryosphere, v.1, pp. 41-58.

Pringle, D.J., Dickinson, W.W., Trodahl, H.J., and Pyne, A.R., 2003, Depth and seasonal variations in the thermal properties of Antarctic Dry Valley permafrost from temperature time series analysis. Journal of Geophysical Research: Solid Earth, v. 108. DOI: 10.1029/2002JB002364

Roth, K., and Boike, J., 2001, Quantifying the thermal dynamics of a permafrost site near Ny-Ålesund, Svalbard. Water Resources Research, v. 37, pp. 2901-2914.

Schaefer, K., Zhang, T., Bruhwiler, L., and Barrett, A.P., 2011, Amount and timing of permafrost carbon release in response to climate warming. Tellus B, v. 63, pp. 165-180.

Silliman, S.E., and Neuzil, C.E., 1990, Borehole determination of formation thermal conductivity using a thermal pulse from injected fluid. Journal of Geophysical Research: Solid Earth, v. 95, pp. 8697-8704.

Somerton, W.H., 1992, Thermal properties and temperature-related behavior of rock/fluid systems. Elsevier, Amsterdam, $256 \mathrm{p}$.

Trodahl, H.J., McGuinness, M.J., Langhorne, P.J., Collins, K., Pantoja, A.E., Smith, I.J., and Haskell, T.G., 2000, Heat transport in McMurdo Sound first-year fast ice. Journal of Geophysical Research, v. 105, pp. $11347-11358$.

Trodahl, H.J., Wilkinson, S.O.F., McGuinness, M.J., and Haskell, T.G., 2001, Thermal conductivity of sea ice: dependence on temperature and depth. Geophysical Research Letters, v. 28, pp. 1279-1282.

Von Herzen, R., and Maxwell, A.E., 1959, The measurement of thermal conductivity of deep-sea sediments by a needle-probe method. Journal of Geophysical Research, v. 64, pp. 1557-1563.

Wilhelm, H., 1990, A new approach to the borehole temperature relaxation method. Geophysical Journal International, v. 103, pp. 469-481.

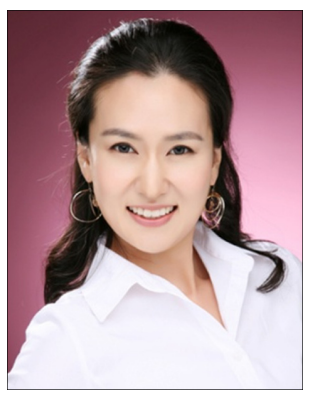

Heejung Kim is Ph.D. of hydrogeology in Seoul National University, Korea. She received her M.S. degree from School of Earth and Environmental Sciences, Seoul National University, Korea. She earned her B.S. degree of Environmental Science and Engineering at Ewha Womans University, Korea. She was awarded the Best Paper Awards from Korean Wetland Society and Korean Society of Soil and Groundwater Environment. She was selected a recipient of Frontier Scholarship from Ewha Womans University. Her research interests include groundwater-stream water interaction, delineation study of hyporheic zone, and microbial diversity in soil and groundwater.

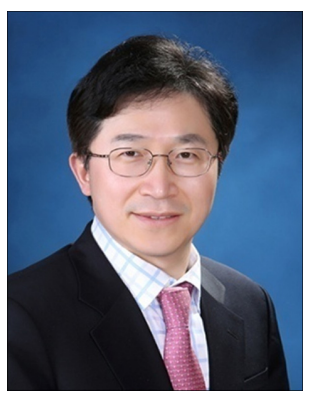

Kang-Kun Lee is a full professor of Hydrogeology and director of SPARC (Science and Policy Advanced Research Course) of the College of Science at Seoul National University, Korea. He received his Ph.D. from Purdue University, West Lafayette, USA. $\mathrm{He}$ has been studying groundwater in Korea since he joined Seoul National University in 1993. He was awarded a medal from the Korean Government at the national ceremony for World Water Day in 2011. He was the president of the Korean Society of Soil and Groundwater Environment (KoSSGE) during 2011-2012 and served as a vice president of the Geological Society of Korea. He is currently the chief editor of Geosciences Journal, served as associate editors for Journal of Hydrology during 2002-2008 and Hydrogeology Journal during 2012-2014. Dr. Lee is appointed as a national representative to the International Association of Hydrological Sciences. Dr. Lee has published over 140 peer-reviewed international journal articles.

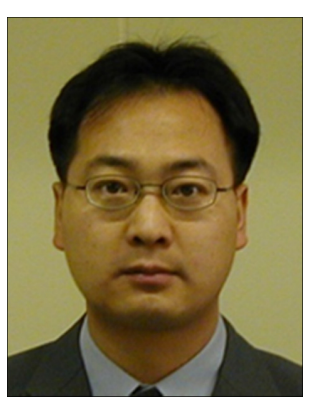

Jin-Yong Lee is a full Professor of Groundwater and Soil Environment at Kangwon National University, Korea. He earned his $\mathrm{PhD}$ degree from Seoul National University. He has published over 200 research papers in international and Korean journals. He was awarded Young Geologist Award, Commendation Award from Environment Minister, Academic Award and Best Paper Award from The Geological Society of Korea, Academic Award from Korea Federation of Water Science and Engineering Societies, Academic and Contribution Awards from Korean Society of Soil and Groundwater Environment. In 2014, he was selected as a Hanrim Leading Scientist by The Korean Academy of Science and Technology. He has served as Editor in Chief of Journal of the Geological Society of Korea and Associate Editor of Geosciences Journal. 